\title{
Qualidade da carne de novilhos terminados em confinamento e abatidos aos 16 ou 26 meses de idade ${ }^{1}$
}

\section{Fernando Kuss ${ }^{2}$, Jorge López ${ }^{3 *}$, João Restle ${ }^{4}$, Júlio Otávio Jardim Barcellos ${ }^{3}$, José Luiz Moletta $^{5}$, Meiby Carneiro de Paula Leite ${ }^{6}$}

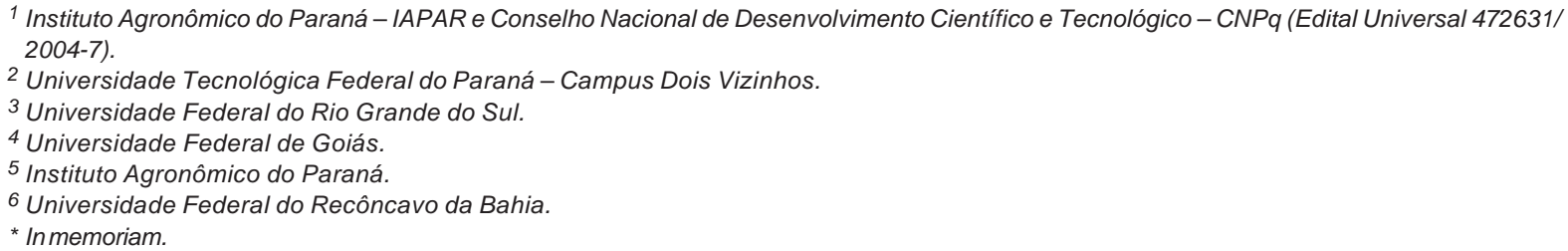

RESUMO - Avaliaram-se as características sensoriais da carne de novilhos não-castrados ou castrados terminados em confinamento e abatidos aos 16 (superjovens) ou 26 (jovens) meses de idade. A dieta com relação volumoso:concentrado de 50:50 continha $11,8 \%$ de proteína bruta e 2,83 Mcal de energia digestível/kg de matéria seca. A maior amplitude do pH final da carne foi observada nos novilhos jovens e a menor, nos superjovens. A carne dos animais não-castrados, independentemente da idade de abate, foi mais escura, mais grosseira e com menor grau de marmorização em comparação à dos castrados. A carne dos animais castrados teve maior perda de líquidos durante o processo de descongelamento em relação à dos não-castrados (8,55 vs 4,99\%). Ocorreu interação entre categoria e sexo do animal para perda de líquido durante a cocção, palatabilidade e suculência. Novilhos jovens não-castrados apresentaram maior quebra à cocção, carne menos palatável e menos suculenta em relação aos jovens castrados e aos superjovens castrados e não-castrados. A redução da idade de abate de 26 para 16 meses de idade, independentemente da condição sexual, melhora a maciez da carne avaliada pelo painel de degustadores.

Palavras-chave: bovinos de corte, cor, maciez, marmoreio, pH, suculência

\section{Meat quality of non-castrate or castrated males feedlot finished and slaughtered at 16 or 26 months of age}

ABSTRACT - It was evaluated in this work the sensorial characteristics of the meat of non-castrate or castrated males feedlot finished and slaughtered at 16 (young steers) or 26 (steers) months old. The diet with 50 roughage: 50 concentrate contained $11.8 \%$ of crude protein and $2.83 \mathrm{Mcal}$ of digestible energy $/ \mathrm{kg}$ of dry matter. The highest amplitude of the final $\mathrm{pH}$ of the meat was noted on the steers, and the lowest on the young steers. The meat of the noncastrate males, regardless to the age at slaughter, was darker, coarser and showed lower marbling degree than the meat of the castrated animals. Thawing loss was higher for the meat of the castrated animals(8.55 vs $4.99 \%)$. There was interaction among categories and sex for cooking loss, palatability and juiciness. Meat of the older non-castrate males showed higher cooking loss, it was less palatable and less juicy regarded to the meat of the older castrated and the younger castrated or non-castrate males. Reduction of slaughtering age from 26 to 16 months old, regardless to sexual condition, improves meat tenderness evaluated by taste panel.

Key Words: beef cattle, color, juiciness, marbling, $\mathrm{pH}$, tenderness

\section{Introdução}

O consumo per capita de carne bovina no mercado interno teve aumento expressivo a partir de 2004. De 2001 a 2003, o consumo médio foi de $35,5 \mathrm{~kg} / \mathrm{pessoa} / \mathrm{ano}$, passando para $42,5 \mathrm{~kg}$ em 2006, o que representa um acréscimo de 19,7\%. Por outro lado, as exportações de carne passaram de 1.259,2 mil para 2.019,3 mil toneladas equivalentes-carcaça, aumento de 60,3\% (MAPA, 2007). Uma das alternativas para suprir esta demanda do mercado interno e externo é a redução da idade de abate dos atuais 36-24 meses para 16-14 meses de idade, por meio da melhoria

Recebido em 22/8/2008 e aprovado em 17/4/2009.

Correspondências devem ser enviadas para: fernandokuss@utfpr.edu.br 
na eficiência biológica no sistema produtivo e qualidade do produto final (Restle \& Vaz, 2003).

Restle \& Vaz (2003) estudaram as características da carne de animais jovens e superjovens e constataram que a redução da idade de abate proporcionou melhora de $15 \%$ na maciez na avaliação pelo painel de degustadores e de 22 \% na determinação objetiva pelo Warner Bratzler Shear. No entanto, em estudo mais recente, Pacheco et al. (2005) não verificaram diferenças entre superjovem e jovem nas principais características consideradas pelo consumidor na compra de determinado corte cárneo (cor, maciez, palatabilidade e suculência).

Outra maneira de aumentar a produção de carne bovina é pela não-castração dos machos. Restle et al. (1994) observaram, em condições exclusivas de pastagem, que machos não-castrados ganharam mais peso e apresentaram carcaças 12,8 e 9,6\% mais pesadas aos 25 meses em comparação aos machos castrados aos 1,5 ou 7 meses de idade, respectivamente. No entanto, a carne dos animais não castrados pode apresentarpH mais elevado(Purchas etal., 2002), o que influencia as características qualitativas da carne.

Ainda existem controvérsias na literatura científica quanto à qualidade da carne de novilhos não-castrados e castrados. Field (1971) e Vaz et al. (2001) descreveram vantagem dos animais castrados sobre os não-castrados quanto à maciez da carne. Todavia, Champagne et al. (1969) e Gerrard et al. (1987) não observaram diferenças na maciez da carne entre castrados e não-castrados. No entanto, em trabalho realizado por Vaz \& Restle (2000), os nãocastrados apresentaram carne mais macia que a dos castrados.

O objetivo neste estudo foi avaliar a qualidade da carne de animais não-castrados ou castrados em confinamento distribuídos em duas idades de abate, 16 meses (superjovem) e 26 meses (jovem).

\section{Material e Métodos}

O experimento foi conduzido na Estação Experimental Fazenda Modelo do Instituto Agronômico do Paraná - FM/ IAPAR, em Ponta Grossa, Região Centro-Sul do estado do Paraná, utilizando-se 32 novilhos não-castrados ou castrados do grupo genético $1 / 2$ Purunã (igual proporção de sangue Angus, Charolês, Caracu e Canchim) +1/2 Canchim. A extirpação dos testículos dos animais castrados foi realizada por meio de castração cirúrgica, aos 7 meses de idade. Os animais foram distribuídos em dois grupos, segundo a idade de abate: 16 meses (superjovem) ou 26 meses (jovem) de idade. Ao início do período experimental, os animais do grupo superjovem apresentavam na média 230,0 e 203,5 kg e os do grupo jovem, 301,5 e 264,5 kg (não- castrados e os castrados, respectivamente). O escore da condição corporal inicial foi de 2,7 e 2,8 pontos; 3, 0 e 2,9 pontos, respectivamente, segundo a classificação proposta por Lowman (1973), em que 1 = muito magro, 2 = magro, 3 = médio, $4=$ gordo e $5=$ muito gordo. A idade inicial dos animais dos grupos superjovem e jovem foi de 9 e 22 meses, respectivamente. O baixo peso inicial dos animais deveu-se à baixa disponibilidade e qualidade da pastagem no período anterior ao início do trabalho, ocasionada por um longo período de seca.

Os animais foram mantidos em confinamento alojados em baias individuais providas de bebedouro de alvenaria e comedouros de madeira e foram alimentados duas vezes ao dia com uma dieta contendo $11,8 \%$ de proteína bruta e 2,83 Mcal de energia digestível/kg de matéria seca (MS), composta de $50 \%$ de volumoso (silagem de milho) e $50 \%$ de concentrado contendo $73,0 \%$ de milho grão, $25 \%$ de farelo de soja, $1 \%$ sal comum e $1 \%$ de calcário calcítico com base na MS.

$\mathrm{O}$ abate dos animais foi pré-estipulado com base na condição corporal (entre 3,5 e 4,0 pontos), visando grau de acabamento preconizado pelos frigoríficos (entre 3 a $6 \mathrm{~mm}$ de gordura subcutânea). O estado corporal foi incluído no modelo como covariável. À medida que a média dos lotes atingiu o escore corporal preconizado, os animais foram submetidos a um jejum de sólidos de 16 horas na fazenda, pesados e transportados em caminhão boiadeiro por $10 \mathrm{~km}$ até o frigorífico comercial, onde procedeu-se ao abate após descanso mínimo de 24 horas, obedecendo ao fluxo de abate normal do estabelecimento.

Ao fim da linha de abate, as duas meias-carcaças foram lavadas, identificadas e pesadas e conduzidas à câmara fria por um período de 24 horas a $2^{\circ} \mathrm{C}$. Antecedendo o resfriamento e a cada duas horas de refrigeração das carcaças foi registrado o $\mathrm{pH}$ do músculo longissimus dorsi entre a $10^{\mathrm{a}}$ e $13^{\mathrm{a}}$ costelas. Decorrido este período, na meia-carcaça direita foi realizado um corte horizontal entre a $12^{\underline{a}}$ e $13^{\mathrm{a}}$ costelas com o intuito de expor o músculo longissimus dorsi para determinação do grau de marmorização, pela quantidade de gordura intramuscular: 1 a $3=\operatorname{traços;~} 4$ a $6=$ leve; 7 a 9 = pequeno; 10 a 12 =médio; 13 a $15=$ moderado; 16 a 18 = abundante; a textura, por meio da observação da granulometria das fibras musculares ( $1=$ muito grosseira; 2 = grosseira; 3 = levemente grosseira; 4 = fina; $5=$ muito fina) e da coloração, avaliada após 30 minutos de exposição do corte ao ar $(1=$ escura; $2=$ vermelho escura; 3 = vermelho levemente escura; 4 = vermelha; $5=$ vermelho-viva), segundo a proposta de Müller (1980).

A porção de músculo longissimus dorsi foi embalada em lâmina de plástico e papel-pardo, identificada e 
imediatamente congelada em congelador comercial a temperatura mínima de $-18^{\circ} \mathrm{C}$ durante 90 dias. Após este período, foram retirados três bifes com espessura de $2,5 \mathrm{~cm}$, da porção cranial da amostra ainda congelada. Dois bifes foram descongelados em refrigerador doméstico por 24 horas e, depois de descongelados, foram assados em forno doméstico até atingir temperatura interna de $70^{\circ} \mathrm{C}$. Um dos bifes foi pesado congelado, descongelado e após o cozimento, para as avaliações do percentual de perdas ao descongelamento e ao cozimento. O outro bife foi destinado à avaliação da maciez, palatabilidade e suculência por intermédio de um painel de cinco degustadores treinados, considerando: 1 = extremamente dura, sem sabor ou sem suculência; 2 = muito dura, deficiente em sabor ou deficiente em suculência; 3 = dura, pouco saborosa ou pouco suculenta; 4 = levemente abaixo da média; $5=$ média, $6=$ levemente acima da média; $7=$ macia, saborosa ou suculenta; $8=$ muito macia, muito saborosa ou muito suculenta; $9=$ extremamente macia, extremamente saborosa ou extremamente suculenta; segundo a metodologia proposta por Müller (1987). O terceiro bife foi destinado à determinação da concentração do colágeno total, segundo metodologia proposta por Amitliche(1980).

O delineamento experimental utilizado foi o inteiramente casualizado. A análise estatística foi realizada com o auxílio do programa SAS (2000). Os dados foram submetidos à análise de normalidade pelo teste ShapiroWilk. As variáveis que apresentaram distribuição normal foram submetidas à análise de variância e o modelo proposto foi analisado utilizando o procedimento GLM, aplicando o MIXED para o pH. As variáveis que não apresentaram distribuição normal foram analisadas utilizando-se a metodologia de Modelos Lineares Generalizados, pelo procedimento GENMOD, com a distribuição gama.

O modelo estatístico utilizado foi: $\mathrm{Y}_{\mathrm{ijk}}=\mu+\mathrm{C}_{\mathrm{i}}+\mathrm{S}_{\mathrm{j}}+\mathrm{CS}_{\mathrm{ij}}$ $+\mathrm{CCF}_{\mathrm{k}}+\mathrm{E}_{\mathrm{ijk}}$; em que: $\mathrm{Y}_{\mathrm{ijk}}=$ variáveis-dependentes; $\mu=$ média de todas as observações; $\mathrm{C}_{\mathrm{i}}=$ efeito da i-ésima categoria animal, em que: $\mathrm{i}=$ jovem ou superjovem; $\mathrm{S}_{\mathrm{j}}=$ efeito da j-ésima condição sexual, em que $\mathrm{j}$ = não-castrado ou castrado; $\mathrm{CS}_{\mathrm{ij}}=$ efeito da interação entre categoria animal e condição sexual; $\mathrm{CCF}_{\mathrm{k}}=$ efeito da covariável condição corporal final e $\mathrm{E}_{\mathrm{ijk}}=$ erro aleatório associado a cada observação.

As médias foram comparadas pelo método dos quadrados mínimos (LSMEANS) a 5\% de significância e as variáveis-dependentes foram submetidas à análise de correlação.

\section{Resultados e Discussão}

A interação entre categoria animal e condição sexual foi significativa para o $\mathrm{pH}$, que apresentou redução linear na carne dos animais jovens castrados (Figura 1). Os demais grupos avaliados também apresentaram redução do $\mathrm{pH}$, porém suas curvas comportaram-se de forma quadrática. De modo geral todos os grupos apresentaram redução na curva de pH normal, semelhante à reportada por Lawrie (2005), atingindo $\mathrm{pH}$ final médio de 5,67 após 22 horas de resfriamento das carcaças.

Com a falência sanguínea no abate dos animais, o aporte de oxigênio deixa de chegar à musculatura, onde o músculo passa a utilizar a via anaeróbica para obter energia para o processo contrátil. Nesse processo, o músculo passa a contar como fonte de energia para essa contração com o glicogênio muscular, reação processada de forma anaeróbica, gerando lactato, que, por sua vez, promove a redução do $\mathrm{pH}$ pos mortem (Price \& Schweigert, 1987). Neste sentido, a concentração de glicogênio no músculo no momento do abate é que definirá a intensidade da redução do $\mathrm{pH}$ (Pardi et al., 1995).

Na categoria jovem, a carne dos animais não-castrados atingiu $\mathrm{pH}$ final superior $(5,90)$ em comparação à carne de seus contemporâneos castrados $(5,44)$. Todavia, na categoria superjovem, a diferença do $\mathrm{pH}$ final entre a carne dos animais castrados e não-castrados foi menor, atingindo médias de 5,75 e 5,59, respectivamente. Antecedendo o embarque dos animais para o frigorífico, os animais jovens não-castrados mostraram-se mais agitados (brigas e tentativas de cobertura) que os superjovens não-castrados. O jejum prolongado pré-abate (16 horas na fazenda +24 horas no frigorífico) acarretou redução do aporte de energia (glicose), que, associado à maior atividade física, pode ter contribuído para menor concentração de glicogênio muscular nos animais jovens não-castrados, o que explicaria a maior diferença de $\mathrm{pH}$ final entre os animais castrados e não-castrados desta categoria. No estudo de Purchas et al. (2002) também foi observado $\mathrm{pH}$ mais elevado no músculo longissimos dorsi dos novilhos não-castrados em relação aos castrados (5,66 vs 5,44, respectivamente) quando abatidos com idade entre 18 e 28 meses.

Segundo Luchiari Filho (2002), em animais bem alimentados e descansados no pré-abate, a concentração de glicogênio no músculo e de 0,8 a $1,0 \%$, ao passo que, se esta concentração diminui para valores inferiores a $0,6 \%$, não ocorre declínio do $\mathrm{pH}$ da carne, permanecendo acima de 6,0, o que irá implicar no aparecimento de carne escura, dura 


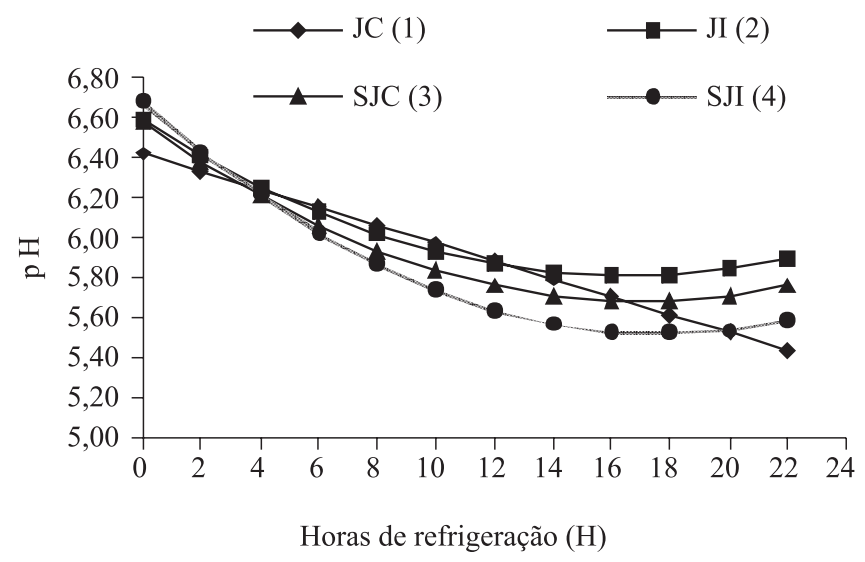

\begin{tabular}{lcccccccccccc}
\hline Item & \multicolumn{1}{c}{ M } & \multicolumn{1}{c}{ Horas de refrigeração (horas) } \\
\hline & 0 & 2 & 4 & 6 & 8 & 10 & 12 & 14 & 16 & 18 & 20 & 22 \\
Jovem castrado & 6,42 & 6,33 & 6,24 & 6,15 & 6,06 & 5,97 & 5,88 & 5,79 & 5,70 & 5,61 & 5,52 & 5,44 \\
Jovem não-castrado & 6,59 & 6,41 & 6,26 & 6,12 & 6,02 & 5,93 & 5,87 & 5,83 & 5,81 & 5,82 & 5,85 & 5,90 \\
Superjovem castrado & 6,58 & 6,38 & 6,21 & 6,06 & 5,93 & 5,83 & 5,76 & 5,71 & 5,68 & 5,68 & 5,71 & 5,76 \\
Superjovem não-castrado & 6,68 & 6,44 & 6,22 & 6,03 & 5,87 & 5,74 & 5,64 & 5,57 & 5,53 & 5,52 & 5,54 & 5,59 \\
\hline
\end{tabular}

${ }^{1} \hat{\mathrm{Y}}=6,41603-0,04456 \mathrm{H} ; \mathrm{P}<0,0001 ; \mathrm{R}^{2}=0,30$.

$2 \hat{\mathrm{Y}}=6,58585-0,09392 \mathrm{H}+0,00285 \mathrm{H}^{2} ; \mathrm{P}<0,0001 ; \mathrm{R}^{2}=0,40$.

$3 \hat{\mathrm{Y}}=6,57792-0,105228+0,00309 \mathrm{H}^{2} ; \mathrm{P}<0,0001 ; \mathrm{R}^{2}=0,59$.

$4 \hat{\mathrm{Y}}=6,68495-0,13203 \mathrm{H}+0,00374 \mathrm{H}^{2} ; \mathrm{P}<0,0001 ; \mathrm{R}^{2}=0,80$.

Figura 1 - Curvas e médias de pH do músculo longissimus dorsi de cada categoria animal e condição sexual durante 22 horas de refrigeração.

e seca. Desta forma, esse maior valor de $\mathrm{pH}$ da carne dos animais jovens não-castrados pode explicar em parte os menores valores para coloração, maciez e suculência também verificados na carne deste grupo (Tabela 1 e 2). A correlação do $\mathrm{pH}$ final com a cor, maciez e suculência foi negativa, de $-0,15,-0,35$ e $-0,20$, respectivamente (Tabela 3 ).

A velocidade e a extensão da redução do $\mathrm{pH}$ pos mortem, segundo Lawrie (2005), são influenciadas por fatores intrínsecos, como a espécie, o tipo de músculo e a variabilidade entre animais, e também por fatores extrínsecos, como a administração de drogas antes do abate e a temperatura ambiente.

A cor da carne foi similar entre os animais jovens e superjovens, classificada entre vermelho levemente escura e vermelha (Tabela 1). A coloração da carne normalmente está associada ao avanço da idade dos animais, por estes apresentarem maior quantidade de mioglobina circulante com mais idade (Boggs \& Mekel, 1981). Cranwell et al. (1996), no entanto, associaram a melhora na coloração da carne de vacas de descarte à menor concentração de mioglobina circulante quando as vacas foram submetidas a dietas com alta concentração energética, resultando em carnes de coloração mais clara. Outros estudos com animais de idade avançada mantidos com dietas com alto nível energético (Schnell et al., 1997; Kuss et al. 2005) descrevem valores de coloração da carne similares aos deste estudo. Em extensa revisão conduzida por Restle \& Vaz (2003) sobre características de carcaça e da carne de animais jovens e superjovens, a cor da carne foi similar entre as duas categorias (3,9 pontos). No trabalho de Pacheco et al. (2005), que também compararam a qualidade da carne de animais jovens e superjovens, foi observado valor similar entre as categorias, porém, com coloração mais clara (média de 4,4 pontos entre os grupos) que a verificada neste estudo (média de 3,5 pontos). Aos olhos do consumidor, carnes

Tabela 1 - Cor, textura e marmoreio da carne de novilhos jovens e superjovens

\begin{tabular}{|c|c|c|c|}
\hline \multirow[t]{2}{*}{ Condição sexual } & \multicolumn{2}{|c|}{ Categoria } & \multirow[t]{2}{*}{ Média } \\
\hline & Jovem & Superjovem & \\
\hline & \multicolumn{2}{|c|}{ Cor (pontos) } & \\
\hline Castrados & $4,4 \pm 0,4$ & $3,7 \pm 0,3$ & $4,1 \pm 0,2 \mathrm{~A}$ \\
\hline Não-castrados & $3,2 \pm 0,3$ & $2,7 \pm 0,4$ & $3,0 \pm 0,2 \mathrm{~B}$ \\
\hline \multirow[t]{2}{*}{ Média } & $3,8 \pm 0,3$ & $3,2 \pm 0,3$ & \\
\hline & \multicolumn{2}{|c|}{ Textura (pontos) } & \\
\hline Castrados & $4,3 \pm 0,3$ & $3,9 \pm 0,2$ & $4,1 \pm 0,1 \mathrm{~A}$ \\
\hline Não-castrados & $3,2 \pm 0,2$ & $3,5 \pm 0,3$ & $3,4 \pm 0,1 \mathrm{~B}$ \\
\hline \multirow[t]{2}{*}{ Média } & $3,8 \pm 0,2$ & $3,7 \pm 0,2$ & \\
\hline & \multicolumn{2}{|c|}{ Marmoreio (pontos) } & \\
\hline Castrados & $7,0 \pm 1,3$ & $9,5 \pm 1,1$ & $8,2 \pm 0,7 \mathrm{~A}$ \\
\hline Não-castrados & $5,1 \pm 1,0$ & $6,4 \pm 1,3$ & $5,7 \pm 0,7 \mathrm{~B}$ \\
\hline Média & $6,0 \pm 0,9$ & $7,9 \pm 1,0$ & \\
\hline
\end{tabular}

A, B Médias seguidas por letras maiúsculas diferentes na coluna para mesma característica diferem $(\mathrm{P}<0,05)$ pelo teste $\mathrm{F}$. 
mais claras são mais aceitáveis, pois a cor vermelha é associada a animais mais jovens, ao passo que cortes cárneos com pontuação inferior a 3,5 pontos, mais escuros, são considerados pelo comprador produto em estado de putrefação, por isso são rejeitados no momento da escolha.

A textura da carne foi similar entre animais jovens $(3,8$ pontos) e superjovens (3,7 pontos) e classificada como levemente grosseira a fina. A textura da carne é avaliada pela granulação da superfície do músculo quando é cortado e constituída de um conjunto de fibras musculares agrupadas em fascículos envolvidos por uma tênue camada de tecido conectivo, o perimísio (Costa et al., 2002). De modo geral, a carne de animais jovens apresenta textura mais fina (Müller, 1987) e, neste caso, a textura está associada à maciez. Similaridade na textura entre animais jovens e superjovens foi relatada por Pacheco et al. (2005).

Não houve diferenca entre as categorias para a quantidade de gordura intramuscular avaliada subjetivamente. A similaridade das médias da quantidade de gordura intramuscular ou de marmorização da carne entre os animais dos grupos jovem e superjovem era esperada, uma vez que ambas as categorias também apresentaram valor semelhante para a espessura de gordura subcutânea, 3,81 e 4,86 mm, respectivamente (Kuss, 2007). Segundo Di Marco et al. (2007), à medida que aumenta a deposição de gordura subcutânea, intensifica-se a deposição da gordura intramuscular. No estudo de Pacheco et al. (2005), os valores de gordura subcutânea e de marmoreio na carne dos animais superjovens foram superiores aos dos animais jovens abatidos com peso semelhante, o que, segundo os autores, esteve associado ao maior período de alimentação em confinamento dos superjovens.

A carne dos animais não-castrados foi mais escura (vermelha levemente escura) e com textura mais grosseira (levemente grosseira) que a dos castrados (vermelha e fina, respectivamente) (Tabela 1). Field (1971) e Seideman et al. (1982) também encontraram valores inferiores, tanto para cor como para a textura para os não-castrados, e relacionaram a coloração ao estresse pré-abate.

A textura mais grosseira na carne dos não-castrados pode estar relacionada ao maior diâmetro da fibra muscular dos não-castrados. Conforme verificado por Purchas et al. (2002) o diâmetro da fibra na carne dos animais não-castrados $(70,4 \mu \mathrm{m})$ foi maior que a dos castrados $(64,9 \mu \mathrm{m})$. Carne com textura mais grosseira de animais não-castrados (3,5 pontos) em comparação à carne de castrados (4,3 pontos) também foi observada por Restle et al. (1996).

Ocorreu maior deposição de gordura intramuscular na carne dos animais castrados (pequena vs leve), acompanhando a deposição de gordura subcutânea na carcaça (4,63 vs 4,04 mm; Kuss et al., 2009). Di Marco et al. (2007) descreveram maior intensidade de deposição de gordura corporal nos animais castrados em comparação aos não-castrados quando abatidos com mesmo peso vivo. Comportamento similar foi descrito por Restle et al. (1996) com valores de marmoreio de 5,9 pontos e 2,8 mm de espessura de gordura subcutânea para os animais castrados e de 3,5 pontos e $0,9 \mathrm{~mm}$, respectivamente, para os não-castrados. Em revisões, Field (1971) e Seideman et al. (1982) também descreveram maior deposição de gordura na carcaça e de marmorização na carne de animais castrados em comparação aos não-castrados.

A carne dos animais castrados teve maior perda de líquidos durante o processo de descongelamento (8,55 vs $4,99 \%$ ) em relação à carne dos não-castrados (Tabela 2). Isso também foi verificado por Vaz et al. (2001), com valores de 8,54 e 3,74\%, respectivamente, para não-castrados e castrados, mas esses autores não relataram as possíveis causas deste resultado. A perda de líquidos durante o descongelamento não teve relação com a suculência da carne, pois a correlação entre as duas variáveis de $-0,05$ $(\mathrm{P}=0,7910)$. Por outro lado, a perda de líquidos durante a cocção, que foi bem maior que a perda durante o descongelamento, teve relação significativa com a suculência da carne $(\mathrm{r}=-0,53 ; \mathrm{P}=0,0017)$ (Tabela 3$)$.

Ocorreu interação categoria $\times$ estado sexual para perda de líquido durante a cocção da carne. Nos animais castrados, não houve diferença entre as duas categorias para perda de líquido durante a cocção, ao passo que nos animais nãocastrados, ocorreu menor perda nos superjovens. Este comportamento, em parte, pode estar associado à menor concentração $(\mathrm{P}>0,05)$ de colágeno total na carne deste grupo (Tabela 2), pois as fibras de colágeno, quando submetidas ao aquecimento, comprimem as fibras musculares envolvidas por esta proteína, ocasionando maiores perdas de líquidos da carne (Lawrie, 2005). A correlação entre a concentração de colágeno no longissimus dorsi e o percentual de perdas na cocção foi positiva $(0,33 ; \mathrm{P}=0,0645)$ (Tabela 3$)$.

$\mathrm{Na}$ avaliação pelo painel de degustadores, a carne dos animais superjovens (classificada entre macia e muito macia) foi mais macia que a dos jovens (classificada como levemente acima da média), o que comprova que é viável a produção de carne com elevado grau de maciez, mesmo sem o processo de maturação, por meio da redução da idade de abate. Esta constatação está de acordo com o abordado por Restle \& $\operatorname{Vaz}$ (2003) sobre a melhoria da qualidade da carne, sobretudo a maciez, por meio da produção de animais superjovens. Estes autores verificaram em 17 estudos com animais superjovens de dez grupos genéticos, que a amplitude da 
Tabela 2 - Características sensoriais da carne de novilhos jovens e superjovens

\begin{tabular}{|c|c|c|c|}
\hline \multirow[t]{2}{*}{ Condição sexual } & \multicolumn{2}{|r|}{ Categoria } & \multirow[t]{2}{*}{ Média } \\
\hline & Jovem & Superjovem & \\
\hline \multicolumn{4}{|c|}{ Quebra ao descongelamento (\%) } \\
\hline Castrados & $8,49 \pm 1,13$ & $8,61 \pm 0,98$ & $8,55 \pm 0,58 \mathrm{~A}$ \\
\hline Não-castrados & $6,04 \pm 0,82$ & $3,95 \pm 1,10$ & $4,99 \pm 0,59 \mathrm{~B}$ \\
\hline Média & $7,26 \pm 0,80$ & $6,28 \pm 0,85$ & \\
\hline \multicolumn{4}{|c|}{ Quebra à cocção $(\%)$} \\
\hline Castrados & $22,29 \pm 3,01 \mathrm{ab}$ & $18,04 \pm 2,61 b c$ & $20,16 \pm 1,53$ \\
\hline Não-castrados & $25,95 \pm 2,19 \mathrm{a}$ & $12,47 \pm 2,93 \mathrm{c}$ & $19,21 \pm 1,58$ \\
\hline Média & $24,12 \pm 2,12$ & $15,25 \pm 2,27$ & \\
\hline \multicolumn{4}{|c|}{ Quebra total de líquidos (\%) } \\
\hline Castrados & $30,78 \pm 2,30 \mathrm{a}$ & $26,64 \pm 2,86 a$ & $28,71 \pm 1,68$ \\
\hline Não-castrados & $31,99 \pm 2,40 \mathrm{a}$ & $16,42 \pm 3,20 \mathrm{~b}$ & $24,20 \pm 1,73$ \\
\hline Média & $31,38 \pm 2,32$ & $21,53 \pm 2,84$ & \\
\hline \multicolumn{4}{|c|}{ Colágeno total (g/100g) } \\
\hline Castrados & $0,176 \pm 0,023$ & $0,166 \pm 0,020$ & $0,171 \pm 0,012$ \\
\hline Não-castrados & $0,184 \pm 0,017$ & $0,129 \pm 0,023$ & $0,156 \pm 0,012$ \\
\hline Média & $0,180 \pm 0,016$ & $0,147 \pm 0,018$ & \\
\hline \multicolumn{4}{|c|}{ Maciez (pontos) } \\
\hline Castrados & $6,2 \pm 0,3$ & $7,4 \pm 0,3$ & $6,8 \pm 0,2$ \\
\hline Não-castrados & $5,8 \pm 0,2$ & $7,8 \pm 0,3$ & $6,8 \pm 0,2$ \\
\hline Média & $6,0 \pm 0,2 \mathrm{D}$ & $7,6 \pm 0,2 \mathrm{C}$ & \\
\hline \multicolumn{4}{|c|}{ Palatabilidade (pontos) } \\
\hline Castrados & $7,0 \pm 0,2 \mathrm{a}$ & $7,2 \pm 0,2 \mathrm{a}$ & $7,1 \pm 0,1$ \\
\hline Não-castrados & $6,3 \pm 0,2 b$ & $7,2 \pm 0,2 \mathrm{a}$ & $6,8 \pm 0,1$ \\
\hline Média & $6,6 \pm 0,2$ & $7,2 \pm 0,2$ & \\
\hline \multicolumn{4}{|c|}{ Suculência (pontos) } \\
\hline Castrados & $6,6 \pm 0,3 \mathrm{a}$ & $7,3 \pm 0,3 \mathrm{a}$ & $6,9 \pm 0,1$ \\
\hline Não-castrados & $5,7 \pm 0,2 b$ & $7,3 \pm 0,3 \mathrm{a}$ & $6,5 \pm 0,1$ \\
\hline Média & $6,2 \pm 0,2$ & $7,3 \pm 0,2$ & \\
\hline
\end{tabular}

A, B Médias seguidas por letras maiúsculas diferentes na coluna para mesma característica diferem $(\mathrm{P}<0,05)$ pelo teste $\mathrm{F}$.

C, D Médias seguidas por letras maiúsculas diferentes na linha para mesma característica diferem $(\mathrm{P}<0,05)$ pelo teste $\mathrm{F}$.

$\mathrm{a}, \mathrm{b}, \mathrm{c}$ Médias seguidas por letras minúsculas diferentes para mesma característica diferem $(\mathrm{P}<0,05)$ pelo teste $\mathrm{F}$.

maciez variou de 6,1 a 8,2 pontos, com média geral de 7,17 pontos; e, em 24 estudos envolvendo animais jovens de 14 grupos genéticos, que a amplitude da maciez variou de 4,5 a 7,8 pontos, com média geral de 6,01 pontos.

Neste estudo a maciez da carne dos superjovens $(7,6$ pontos) foi maior e a carne dos jovens ( 6,0 pontos) levemente acima das médias observadas por Restle \& Vaz (2003), respectivamente, para as duas categorias. No estudo de Pacheco et al. (2005), não foram encontradas diferenças na maciez e palatabilidade entre animais jovens e superjovens; no entanto, a carne dos jovens mostrou-se menos suculenta (6,8 vs 7,3 pontos, respectivamente).

Carne menos palatável e menos suculenta foi registrada nos animais jovens não-castrados e a causa deste fato foi a maior perda de líquidos e gordura da carne desses animais durante a cocção. As correlações entre a quebra à cocção e a maciez, palatabilidade e suculência neste estudo foram

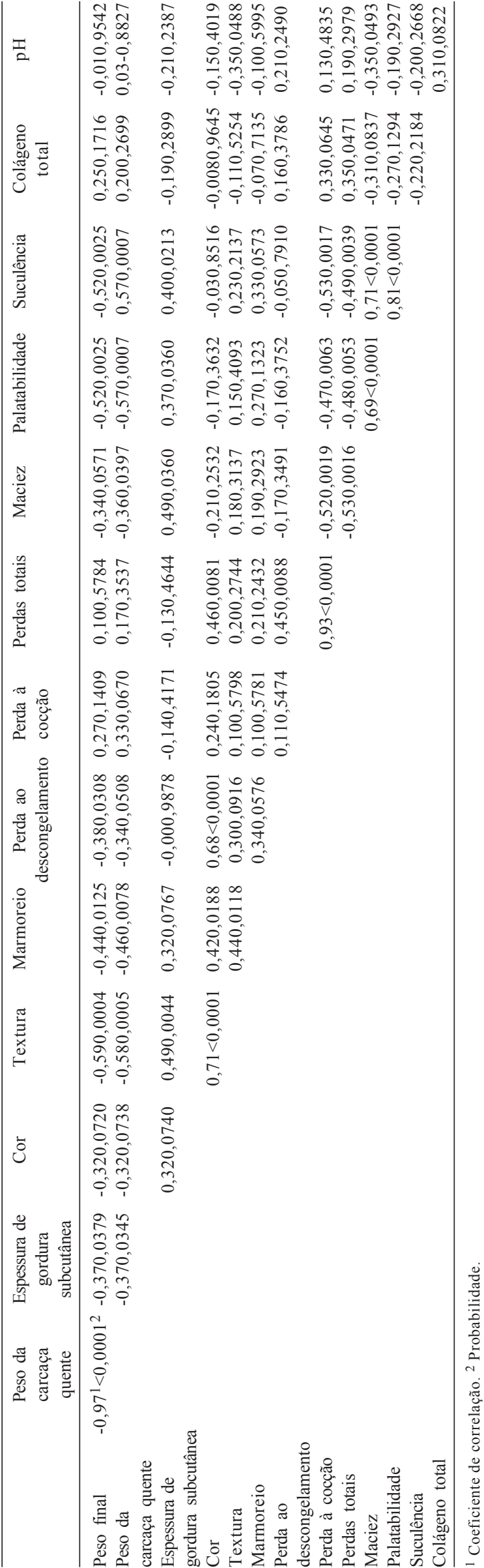

R. Bras. Zootec., v.39, n.4, p.924-931, 2010 
negativas (Tabela 3). De maneira geral, as carnes que apresentaram maior perda total de líquidos (no descongelamento e no cozimento) foram de menor qualidade, menos macias $(r=-0,53)$, palatáveis $(r=-0,48)$ e suculentas $(r=-0,49)$.

Ocorreu interação entre categoria animal e condição sexual para palatabilidade e suculência da carne. De maneira geral, a carne dos animais jovens não-castrados foi menos macia, palatável e suculenta que a dos jovens castrados, ao passo que, na categoria superjovem, os valores de maciez, palatabilidade e suculência foram similares entre castrados e não-castrados. Esta constatação comprova que, ao reduzir a idade de abate dos 26 para os 16 meses, a carne proveniente de animais não-castrados melhora significativamente, tornando-se semelhante à de novilhos superjovens castrados. Müller \& Restle (1983) e Restle et al. (1996), em pesquisa com animais abatidos aos 25 meses, também descreveram carne menos macia para os nãocastrados. No entanto, nos estudos de Vaz \& Restle (2000) e Vaz et al. (2001), carne mais macia, palatável e suculenta foi observada para os não-castrados. Segundo os autores, esse resultado pode ter sido devido à susceptibilidade ao estresse pré-abate dos animais não-castrados e à produção de carne tipo "DFD" (do inglês "dark, firm and dry", ou seja, escura, consistente e não-exsudativa), já que a carne destes animais apresentou maior retenção de água e foi mais escura.

Gerrard et al. (1987) descreveram associação entre a condição sexual e a idade de abate dos animais para maciez da carne. Esses autores relataram ainda que, nos animais castrados, a maciez da carne reduziu de forma linear com o avanço da idade de abate (9, 12, 15 e 18 meses), ao passo que a maciez da carne dos não-castrados variou com o aumento da idade: foi mais macia que a dos castrados aos 12 e 18 meses de idade.

\section{Conclusões}

A carne de novilhos não-castrados, independentemente da idade de abate, é mais escura, de textura mais grosseira e com menor grau de marmoreio que a de novilhos castrados. A redução da idade de abate de 26 para 16 meses proporciona carne mais macia. A carne de animais jovens não-castrados é menos palatável e menos suculenta.

\section{Referências}

AMITLICHE. UNTERSUCHUNGS. VERDAHREN NACH 35 MEG. Untersuchung von lebensmitteln. Bestimmung des hidroxiprolingehaltes in Fleisch und Fleischusergnissen, L 06.00-8, September, 1980, p.1-3.

BOGGS, D.L.; MERKEL, R.A. Live animal: carcass evaluation and selection manual. Iowa: Michigan State University, 1981. $199 \mathrm{p}$.
CASACCIA, J.L.; PIRES, C.C.; RESTlE, J. Confinamento de bovinos não-castrados ou castrados de diferentes grupos genéticos. In: REUNIÃO ANUAL DA SOCIEDADE BRASILEIRA DE ZOOTECNIA, 30., 1993, Rio de Janeiro. Anais... Rio de Janeiro: Sociedade Brasileira de Zootecnia, 1993. p.468.

CHAMPAGNe, J.R.; CARPENTER, J.W.; HENTGES, J.F. et al. Feedlot performance and carcass characteristics of young bulls and steers castrated at four ages. Journal of Animal Science, v.29, n.6, p.887-890, 1969.

COSTA, E.C.; RESTLE, J.; VAZ, F.N. et al. Composição física da carcaça, qualidade da carne e conteúdo de colesterol do músculo Longissimus de novilhos Red Angus superjovem terminados em confinamento, abatidos com diferentes pesos. Revista Brasileira de Zootecnia, v.31, n.1, p.417-428, 2002 (supl.).

CRANWELL, C.D.; UNRUH, J.A.; BRETHOUR, J.R. et al. Influence of steroid implants and concentrate feeding on carcass and longissimus muscle sensory and collagen characteristics of cull beef cows. Journal of Animal Science, v.74, p.1777-1783, 1996.

DI MARCO, O.N.; BARCELLOS, O.J.; COSTA, E.C. Crescimento de bovinos de corte. Porto Alegre: UFRGS, 2007. 276p.

FIELD, R.A. Effect of castration on meat quality and quantity. Journal of Animal Science, v.32, n.5, p.849-858, 1971.

GERRARD, D.E.; JONES, S.J.; ABERLE, E.D. et al. Collagen stability, testosterone secretion and meat tenderness in growing bulls and steers. Journal of Animal Science, v.65, p.1236-1242, 1987.

KUSS, F.; LÓPEZ, J.; BARCELlOS, J.O.J. Características da carcaça de novilhos não-castrados ou castrados terminados em confinamento e abatidos aos 16 ou 26 meses de idade. Revista Brasileira de Zootecnia, v.38, n.3, p.515-522, 2009.

KUSS, F.; RESTLE, J.; BRONDANI, I.L. et al. Composição física da carcaça e qualidade da carne de vacas de descarte de diferentes grupos genéticos terminadas em confinamento com distintos pesos. Revista Brasileira de Zootecnia, v.34, n.4, p.1285-1296, 2005.

LAWRIE, R.A. Ciência da carne. 6.ed. São Paulo: Artmed, 2005. $384 \mathrm{p}$.

LOWMAN, B.G.; SCOTT, N.; SOMERVILLE, S. Condition scoring beef cattle. Edinburgh: East of Scotland College of Agriculture, 1973. 8p.

LUCHIARI FILHO, A. O aparecimento de carne escura em bovinos. Beef Point, 2002. Disponível em: <http:// www.beefpoint.com.br>. Acesso: 1/6/2007.

MINISTÉRIO DA AGRICULTURA, PECUÁRIA E ABASTECIMENTO - MAPA. [2007]. Disponível em: <http://www.agricultura.gov.br>. Acesso: 15/7/2007.

MÜLLER, L. Normas para a avaliação de carcaças e concurso de carcaças de novilhos. 2.ed. Santa Maria: Imprensa Universitária, 1987. $31 \mathrm{p}$.

MÜLLER, L. Normas para avaliação de carcaças e concurso de carcaças de novilhos. 1.ed. Santa Maria: Universidade Federal de Santa Maria, 1980. 31p.

MÜLLER, L.; RESTLE, J. Carcass characteristics of steers and young bulls. In: EUROPEAN CONGRESS OF MEAT RESEARCH WORKERS, 29., 1983, Parma. Proceedings... Parma: CERCA, 1983. p.530-535.

PACHECO, P.S.; RESTLE, J.; SILVA, J.H.S. Composição física da carcaça e qualidade da carne de novilhos jovem e superjovem de diferentes grupos genéticos. Revista Brasileira de Zootecnia, v.34, n.5, p.1691-1703, 2005b.

PARDI, M.C.; SANTOS, J.F.; SOUZA, E.R. et al. Ciência, higiene e tecnologia da carne. Goiânia: UFG, 1995. 586p.

PRICE, J.F.; SCHWEIGERT, B.S. The science of meat and meat products. 3.ed. Westport: Food \& Nutrition Press, 1987. 639p.

PURCHAS, R.W.; BURNHAM, D.L.; MORRIS, S.T. Effects of growth potential and growth path on tenderness of beef 
longissimus muscle from bulls and steers. Journal of Animal Science, v. 80, p.3111-3221, 2002.

RESTLE, J.; FLORES, J.L.C.; VAZ, F.N. et al. Desempenho em confinamento, do desmame ao abate aos quatorze meses, de bovinos não-castrados ou castrados, produzidos por vacas de dois anos. Ciência Rural, v.27, n.4, p.651-655, 1997.

RESTLE, J.; GRASSI, C.; FEIJÓ, G.L.D. Características das carcaças e da carne de bovinos não-castrados ou submetidos a duas formas de castração, em condições de pastagem. Revista Brasileira de Zootecnia, v.25, n.2, p.334-343, 1996.

RESTLE, J.; GRASSI, C.; FEIJÓ, G.L.D. Características de carcaça de bovinos não-castrados ou castrados em diferentes idades. Pesquisa Agropecuária Brasileira, v.29, n.10, p.1603-1607, 1994.

RESTLE, J.; VAZ, F.N. Eficiência e qualidade na produção de carne bovina. In: REUNIÃO ANUAL DA SOCIEDADE BRASILEIRA DE ZOOTECNIA, 40., 2003, Santa Maria. Anais... Santa Maria: SBZ. (CD-ROM).
SCHNELL, T.D.; BELK, K.E.; TATUM, J.D. et al. Performance, carcass, and palatability traits for cull cows fed high-energy concentrate diets for $0,14,28,42$ or 56 days. Journal of Animal Science, v.75, p.1195-1202, 1997.

SEIDEMAN, S.C.; CROSS, H.R.; OLTJEN, R.R. et al. Utilization of the intact male for red meat production: a review. Journal of Animal Science, v.55, n.4, p.826-841, 1982.

STATISTICAL ANALYSIS SYSTEM - SAS. SAS/STAT. User's guide: statistics, versão 8.1. 4.ed., v.2, Cary: SAS Institute, 2000. (CD-ROM).

VAZ, F.N.; RESTLE, J. Aspectos qualitativos da carcaça e da carne de machos Hereford, inteiros ou castrados, abatidos aos quatorze meses. Revista Brasileira de Zootecnia, v.29, n.6, p.1894-1901, 2000.

VAZ, F.N.; RESTLE, J.; FEIJÓ, G.L.D. et al. Qualidade e composição química da carne de bovinos não-castrados ou castrados de diferentes grupos genéticos Charolês x Nelore. Revista Brasileira de Zootecnia, v.30, n.2, p.518-525, 2001. 